\section{Questión}

Periodismo / Comunicación ISSN 1669-6581
- Av. $44 \mathrm{~N}^{\circ} 676,1^{\circ}$ piso

CP 1900 - La Plata - Argentina

www.perio.unlp.edu.ar/question

Santa Cruz en la pandemia. Solidaridad a flor de piel

Alfredo Fernández

DOI: https://doi.org/10.24215/16696581e311

\title{
Santa Cruz en la pandemia
}

Solidaridad a flor de piel

\section{Santa Cruz in the pandemic}

Solidarity in the skin

Alfredo Fernández / afernandez@uarg.unpa.edu.ar Docente Investigador UNPA UARG

Santa Cruz vive, como todas las provincias del país, la situación particular del aislamiento social preventivo y obligatorio. Si bien a la fecha la mayor parte de personas con coronavirus son de El Calafate, y vinculadas a turistas extranjeros, las acciones de prevención se desarrollan en todo el territorio.

Ni bien se conoció el decreto del aislamiento el 19 de marzo último, comenzaron las acciones solidarias. Por ejemplo, la Unidad Académica Río Gallegos (UARG) de la UNPA (Universidad Nacional de la Patagonia Austral) convocó a los pocos días a un Banco de Voluntariado, a fin de relevar posibles aportes a la comunidad universitaria para la atención de tareas derivadas de la emergencia sanitaria por la pandemia del coronavirus COVID-19. Los voluntarios acompañan en una colaboración directa con las áreas del Estado Nacional, Provincial o Municipal en tareas de atención primaria en salud, acompañamiento o intervenciones en familia en riesgo, u otras que sean demandadas para la atención de la situación de emergencia sanitaria. En el primer día de convocatoria se inscribieron casi 300 voluntarios, entre personal docente, no docente y alumnos de distintas carreras. 
Otra de las acciones emprendidas fue la confección de elementos de protección para el personal de salud. Cada kit estaba comprendido por botas, camisolín, barbijo y cofia. La tarea se realizó bajo la supervisión de la Comisión de Seguimiento integrada por docentes de la Escuela de Enfermería y profesionales del área de Higiene y Seguridad de la UARG.

Del plantel de voluntarios se convocó a más de 30 para armar moldes con los modelos aportados por el Hospital Regional de Río Gallegos y se distribuyeron junto a los materiales necesarios, telas, elástico, cinta e hilo. Así cada voluntario, desde su casa y en la medida en que la UARG fue teniendo acceso a los materiales, comenzaron a preparar los kits que incluyen botas, camisolín, barbijo y cofia.

La solidaridad también se manifestó a través de la campaña de recolección para estudiantes que no tienen PC. A tal fin se invitó a la comunidad universitaria a colaborar con la donación de tablets, notebooks, netbooks o PCs para ser acondicionadas y entregadas a alumnos de la Universidad que no cuentan con recursos informáticos. De esta manera se busca facilitar la continuidad en los estudios de los alumnos, que actualmente se realizan de forma no presencial.

Como la Universidad, otras entidades se abocaron también a brindar acompañamiento y desarrollar determinadas acciones solidarias. Diversas organizaciones asisten diariamente a barrios carecientes con raciones de alimentos y elementos de higiene para que puedan ser distribuidos entre las familias. En un acuerdo firmado entre un sindicato, el Ejército Argentino y la municipalidad local se distribuyen más de 1500 raciones diarias de comida caliente en sectores más necesitados. 